\title{
EFFECT OF AMBON BANANA (MUSA ACUMINATA COLLA) ON EMESIS GRAVIDARUM
}

\author{
Erike Yunicha Viridula \\ Diploma Program in Midwivery, Faculty Health Science, Kadiri University
}

\begin{abstract}
Background: Emesis gravidarum is a common symptom of first trimester pregnancy. Emesis (vomiting) usually occurs in the morning, so it is often known as morning sickness. But emesis gravidarum can occur at anytime and at night. A survey showed about $70 \%$ of first trimester pregnant women experience emesis gravidarum. This study aimed to determine the effect of Ambon banana (musa acuminata colla) on emesis gravidarum.

Subjects and Method: This was a quasi experiment, using before and after intervention with no comparison group. This study was conducted at Aura Syifa Hospital, Kediri, East Java. A sample of 16 pregnant women of first trimester were selected for this study. The dependent variable was frequency of vomiting. The indepedent variable was Ambon banana (musa acuminata colla). The data was collected by questionnaire and observation. Frequency of vomiting before and after intervention were tested by paired t-test.

Results: Frequency of vomiting before consumption of Ambon banana decreased from mean $=2.81$ to mean $=1.75$ after consumption of Ambon banana, and it was statistically significant $(\mathrm{p}=0.001)$.
\end{abstract}

Conclusion: Ambon banana is effective to reduce emesis gravidarum in pregnant women of first trimester.

Keywords: Ambon banana, emesis gravidarum, pregnant women, first trimester

Correspondence: Erike Yunicha Viridula. Diploma Program in Midwivery, Faculty Health Science, Kadiri University, Jl. Selomangleng No.1, Kediri, East Java. 